\title{
Femoral Shaft Fractures in Pediatric Age: Treatment Strategies and Results
}

\author{
Carvalho M*, Alves C, Cardoso PS, Balacó I, Ling TP and Matos G \\ Deparment of Pediatric Orthopaedics - Hospital Pediátrico, Coimbra, Portugal \\ *Corresponding author: Marcos Carvalho, Deparment of Pediatric Orthopaedics - Hospital Pediátrico Coimbra, Av Afonso Romão, \\ 3000-602 Coimbra, Portugal
}

\begin{abstract}
Purpose: Femoral shaft fractures represent $1.4-1.7 \%$ of all fractures in the pediatric population and may be associated with significant morbidity. The purposes of this study are to verify if increasing age and weight are predictive factors of associated injuries and complications in children with femoral shaft fractures.

Methods: Retrospective study, including patients with age below 16 years old, admitted in our Department between 2011 2015, with the diagnosis of femoral shaft fracture. Patient demographics, fracture characteristics, associated injuries, treatment methods, time to union, follow-up and complications were collected from the medical records. Statistical significance was set for level of $\mathrm{p}<0.05$.

Results: Sixty patients were included. There was a male predominance [n=40]. Age at the time of injury was $6.3 \pm 4.9 y e a r s$ old. The 61 femoral shaft fractures: observed affected different areas: 12-proximal; 43-middle; 6-distal. The most common etiology was direct trauma after a fall and traffic accident. Associated lesions were found to be significantly higher in older $(p=0.01)$ and heavier $(p=0.009)$ patients. Conservative treatment was the option for $62 \%$ of all fractures. The minimum age to surgery was 6 years old and rigid trochanteric entry nailing was only considered above 10 years old. Patients treated conservatively had a significant lower weight $(16.4 \pm 8.4 \mathrm{Kg})$ than those operated on $(42.5 \pm 13.8 \mathrm{Kg})[\mathrm{p}<0.001]$. Mean follow-up time was $50.4 \pm 56.8$ weeks and complications were reported in $15 \%$ of patients. We did not verify any statistically significant differences between post treatment complications and the treatment method $(\mathrm{p}=0.803)$.
\end{abstract}

Conclusions: The age, weight and associated lesions were considered significant factors when choosing the treatment method.

Keywords: Pediatric Femur Shaft Fracture; Age; Weight: Associated Injuries; Complications

\section{Introduction}

Fractures affect $10 \%-25 \%$ of children sustaining a musculoskeletal injury [1]. Different risk factors have been reported, such as age, sex, season, risk-taking behavior, bone mineral density (BMD), sports, but also violence, ethnicity and socioeconomic status [2-7]. Overweight and obesity seem to increase the fracture risk [8$10]$, likely due to lower bone mass relative to body size and greater mechanical load caused by falls or reduced body balance [4-13]. Femoral shaft fractures are among the most common major injuries in pediatric age representing $1.4-1.7 \%$ of all fractures in pediatric population [14-16]. The etiology of the injury includes falls, motor vehicle accidents, sports injuries and child abuse. Non-accidental injury has been reported as the leading cause of femur fractures in children less than 1 year old [17-19] and the AAOS recommends that children younger than 36 months with a diaphyseal femur fracture should be evaluated for child abuse [20]. The ideal treatment for a pediatric diaphyseal femur fracture is highly dependent upon age and size of the child but it should also consider weight, associated injuries, fracture pattern and mechanism of lesion [1422]. The treatment should focus on getting the fracture to heal in an adequate alignment according to age, avoiding complications such as nonunion, delayed union, angular or rotational deformities, limb length discrepancy, infection, neurovascular injury, disruption of the growth plate, muscle weakness, and/or compartment syndrome [21]. At the same time, the treatment should also be comfortable for the patient and convenient for the family, causing the least negative psychological and socioeconomical impact [23].

Femoral shaft fractures are one of the most common pediatric orthopedic injury requiring hospitalization. Casting with or without 
preceding traction has been the mainstay of treatment in the past, leading to healing and remodeling with good long-term outcomes [14-25]. However, in the last decades there has been a gradual shift towards operative treatment in order to achieve a quicker recovery, shorter rehabilitation time and, simultaneously reducing the morbidity associated with prolonged immobilization [14-26]. With the development of age-adequate fixation devices, several different procedures are available for stabilization of femoral shaft fractures in children, such as external fixators, submuscular plates, rigid intramedullary nails and flexible intramedullary nails [1423]. Age, weight, fracture personality and skeletal maturity are key factors in guiding treatment options in our institution. Usually, with advancing age and skeletal maturity, acceptable values for angulation and shortening of the fracture decrease, as there is less potential for remodeling. For patients from birth to 2 years, up to $30^{\circ}$ of angulation in all planes and $20 \mathrm{~mm}$ of shortening can be accepted. In patients aged 2 to 5 years one can accept up to $15^{\circ}$ of Varus/valgus, $20^{\circ}$ of anterior/posterior angulation and $15 \mathrm{~mm}$ of shortening. In patients from 6 to 10 years, it is acceptable $10^{\circ}$ of Varus/valgus, $15^{\circ}$ of anterior/posterior and $15 \mathrm{~mm}$ of shortening For patients older than 11 years of age, the surgeon can only allow $5^{\circ}$ of Varus/valgus, $10^{\circ}$ of anterior/posterior of angulation and up to $10 \mathrm{~mm}$ of shortening [27].

Nonoperative treatment is mainly indicated for children under 5-6 years of age and options include Pavlik harness, early traction (skin and/or skeletal) with delayed Spica casting, and early fracture manipulation with Spica casting [14-28]. Pavlik harness use is indicated for patients less than 6 months old [20]. Early closed reduction and hip Spica cast has become the primary treatment for patients between the age of 6 months and 5 years, with less than $2 \mathrm{~cm}$ of fracture shortening. Isolated traction is still an option for management, although less popular nowadays [20]. If, during the treatment, the fracture shortening increases beyond $2 \mathrm{~cm}$, a change in the treatment plan must be considered [20].

Operative treatment is usually reserved for children over the age of 5 or 6 years, but must be considered whenever there is unacceptable deformity, polytrauma, open fracture, neurovascular injury, pathologic fracture or body habitus not amenable to casting [28]. Surgical treatment should be considered when conservative treatment fails or there are associated head injury or multiple injuries [14-23]. Operative stabilization and fixation options, include flexible/elastic intramedullary nailing, rigid intramedullary nailing, internal plate fixation and external fixation. The use of flexible/elastic nails is indicated to treat children age 5 to 11 years old weighing less than $49 \mathrm{Kg}$ [20-29]. Flexible interlocking intramedullary nailing (FIIN) is an option for patients between 5 and 11 years of age weighing more than $45.5 \mathrm{Kg}$, but too skeletally immature for rigid nailing [28-30]. Rigid intramedullary nailing and submuscular plating are options for patients older than 11 years old with diaphyseal femur fractures. Trochanteric entry point should be used in antegrade rigid nailing and piriformis or near piriformis entry should be avoided because of the risk of osteonecrosis of the femoral head or growth plate disturbances [28-31]. Indirect reduction with submuscular bridge plating is an option for comminuted fractures, particularly in patients older than 5 years [24-32]. On the other way, direct open reduction with compressive plating remains a rare option for fractures not suitable to closed or indirect reduction [14]. External fixation is useful when skin integrity is compromised and for damage control but has a high rate of malunion and pin tract infection [20-33]. Complications related to treatment include femoral head osteonecrosis (reported uncommonly, after rigid intramedullary nailing), malunion (more prevalent with external fixation and flexible/elastic intramedullary nailing in heavier children), nonunion, implant migration or prominence (mostly with flexible/ elastic intramedullary nailing), infection, neurovascular injury, refracture, venous thromboembolism and fat emboli syndrome [28]. The main aim of our study was to verify if age and weight are predictive factors of associated injuries and complications in children with femoral shaft fracture.

\section{Methods}

We performed a retrospective cohort study, including all patients age 0-16 years old, admitted to our institution, in the period 2011-2015, with a diagnosis of femoral shaft fracture. Patients with syndromic or neuromuscular pathology were excluded. Patient records were searched to collect data on age, weight, gender, side of fracture, etiology of injury, pattern and location of fracture, associated lesions, type of treatment, complications, fracture healing and result at final follow-up. Statistical analysis was performed using the IBM SPSS Statistics 23.0 software. Data were shown as mean \pm standard deviation for the continuous variables, median (minimum-maximum) for ordinal variables, and frequency, with a percentage for categorical variables. Due to the small sample size and inability to assume normal data distribution, the Fisher's exact test was selected for analysis of categorical variables and the Mann-Whitney and Kruskal-Wallis tests used to compare continuous variables. A significance level of $p<0.05$ was set for considering statistically significant differences.

\section{Results}

Sixty patients with 61 femoral shaft fractures were included in this study. A male predominance $[\mathrm{n}=40]$ was observed. Mean age at the time of injury was $6.3 \pm 4$.9years. Of the 61 femoral shaft fractures identified, 13 were proximal: 42 mid-diaphyseal and 6 distal. The most common etiology of injury was direct trauma after a fall [ $n=25]$ followed by traffic accident [ $n=16]$, indirect trauma [ $n=12]$, hit-by-car [n=7] and child abuse [n=1] (Figure 1). We verified a greater number of right sided fractures [n=34] and the most common pattern of fracture was transverse [ $n=29]$, followed by spiral [ $n=19]$ and oblique [ $n=13]$. At the time of fracture, $18 \%$ of the patients [ $n=11]$ had also other associated lesions: other fractures $[n=7]$, severe thoracic trauma $[n=3]$, head trauma with subdural hematoma [ $n=3]$, renal trauma $[n=2]$, splenic trauma $[n=1]$, hepatic trauma [n=1] and braquial plexus neuropraxia [n=1] (Table 1). The occurrence of associated lesions was significantly higher in older ( $\mathrm{p}=0.01)$ and heavier ( $\mathrm{p}=0.009)$ patients. The relative risk of associated lesions at the time of fracture was 1.4 times higher in patients with more than 5 years old when compared to those who were younger [RR=1,384 (IC95\%: 1.058-1.812), $\mathrm{p}=0.008$ ]. 

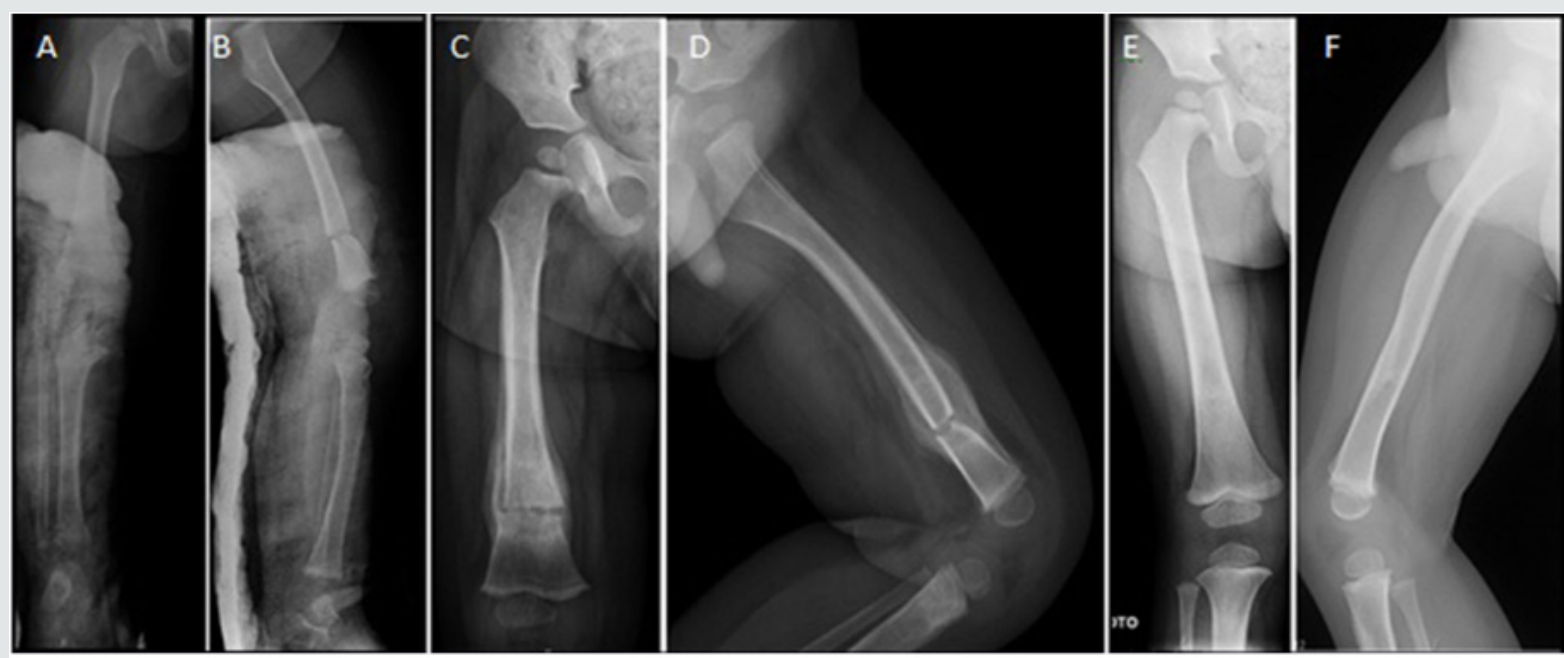

Figure 1: AP and lateral X-Rays of the right limb of a baby boy 5 months old showing a transverse distal diaphyseal femur fracture after child abuse. A, B) Transverse distal diaphyseal femur fracture treated with cruropodalic cast; C, D) One month after fracture with radiographic evidence of fracture union with abundant callus formation; E, F) After 1 year of the fracture with radiographic healing in proper alignment with complete remodeling of the bone.

Table 1: Characteristics of pediatric patients with diaphyseal femur fractures.

\begin{tabular}{|c|c|}
\hline \multicolumn{2}{|c|}{ Variable } \\
\hline Age (years), mean (sd) & $6.3( \pm 4.9)$ \\
\hline $\operatorname{Sex}(M),(n, \%)$ & $40(66.7 \%)$ \\
\hline Weight (Kg), mean (sd) & $26.2( \pm 16.6)$ \\
\hline \multicolumn{2}{|l|}{ Fractured limb (n, \%) } \\
\hline Right & $34(55.7 \%)$ \\
\hline Left & $27(44.3 \%)$ \\
\hline \multicolumn{2}{|l|}{ Diaphyseal segment fracture (n, \%) } \\
\hline Proximal & $13(21.3 \%)$ \\
\hline Middle & $42(68.9 \%)$ \\
\hline Distal & $6(9.8 \%)$ \\
\hline \multicolumn{2}{|l|}{ Fractured type $(n, \%)$} \\
\hline Transverse & $29(47.6 \%)$ \\
\hline Spiral & $19(31.1 \%)$ \\
\hline Oblique & $13(21.3 \%)$ \\
\hline \multicolumn{2}{|l|}{ Cause of injury (n, \%) } \\
\hline Fall & $25(41.0 \%)$ \\
\hline Motor vehicle accident & $16(26.2 \%)$ \\
\hline Indirect trauma & $12(19.7 \%)$ \\
\hline Hit-by-car & $7(11.5 \%)$ \\
\hline Child abuse & $1(1.6 \%)$ \\
\hline Patients with Associated Lesions (n, \%) & $11(18.0 \%]$ \\
\hline Other musculoskeletal fracture & $7(38.9 \%)$ \\
\hline Severe thoracic trauma & $3(16.6 \%)$ \\
\hline Head trauma with subdural hematoma & $3(16.6 \%)$ \\
\hline Renal trauma & $2(1.1 \%)$ \\
\hline Splenic trauma & $1(5.6 \%)$ \\
\hline Hepatic trauma & $1(5.6 \%)$ \\
\hline Braquial plexus neuropraxia & $1(5.6 \%)$ \\
\hline
\end{tabular}




\begin{tabular}{|c|c|}
\hline Treatment (n, \%) & $23(37.7 \%)$ \\
\hline Surgery & $19(82.6 \%)$ \\
\hline Nails & $2(8.7 \%)$ \\
\hline External Fixator & $2(8.7 \%)$ \\
\hline Submuscular plate & $38(62.3 \%)$ \\
\hline Conservative & $29(76.3 \%)$ \\
\hline Spica Cast & $9(23.7 \%)$ \\
\hline Cruropodalic & $8(14.8 \%)$ \\
\hline
\end{tabular}

In terms of treatment, $62 \%$ of the fractures were treated conservatively either with spica cast [76\%] or cruropodalic cast [24\%]. Surgical treatment was performed in 38\% of the fractures [n=23]: 19 nails [9] elastic nails, of which 7 were retrogade (Figure 2), and 10 antegrade rigid nails with trocantheric entry (Figure 3) 2 external fixators and 2 submuscular plates (Figure 4) (Table 1). The minimum age to surgery was 6 years and rigid trocantheric entry nailing was only considered for children older than 10 years. We verified a statistically significant difference between treatment groups regarding body weight $(42.5 \pm 13.8 \mathrm{Kg}$ in the operative group and $16.4 \pm 8.4 \mathrm{Kg}$ in the nonoperative group $[\mathrm{p}<0,001])$ and age $(11.3 \pm 2.6 y e a r s$ in operative group and $3.3 \pm 3$.5years in nonoperative group $[\mathrm{p}<0,001])$.
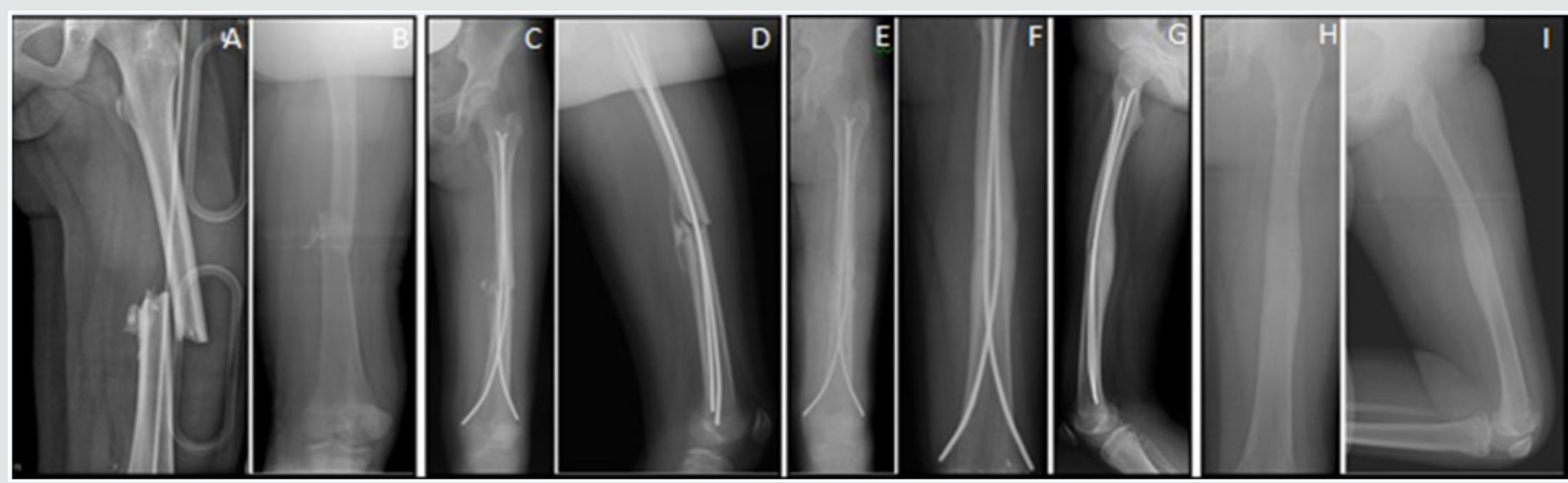

Figure 2: AP and lateral X-Rays of the left limb of an 11 years old girl showing a transverse midshaft femur fracture after a traffic accident. A, B) Transverse midshaft femur fracture with Varus displacement and shortening $>2 \mathrm{~cm}$; C, D) Six weeks after fracture and operative stabilization with a retrograde titanium elastic nailing, a good fracture reduction and apposition of the fragments with bone callus formation can be seen; E, F, G) Radiographic evidence of union with no displacement or shortening 12 months after fracture; H, I) Radiographic control 14 months after fracture and 1 month after extraction of the nail with a complete bone remodeling.
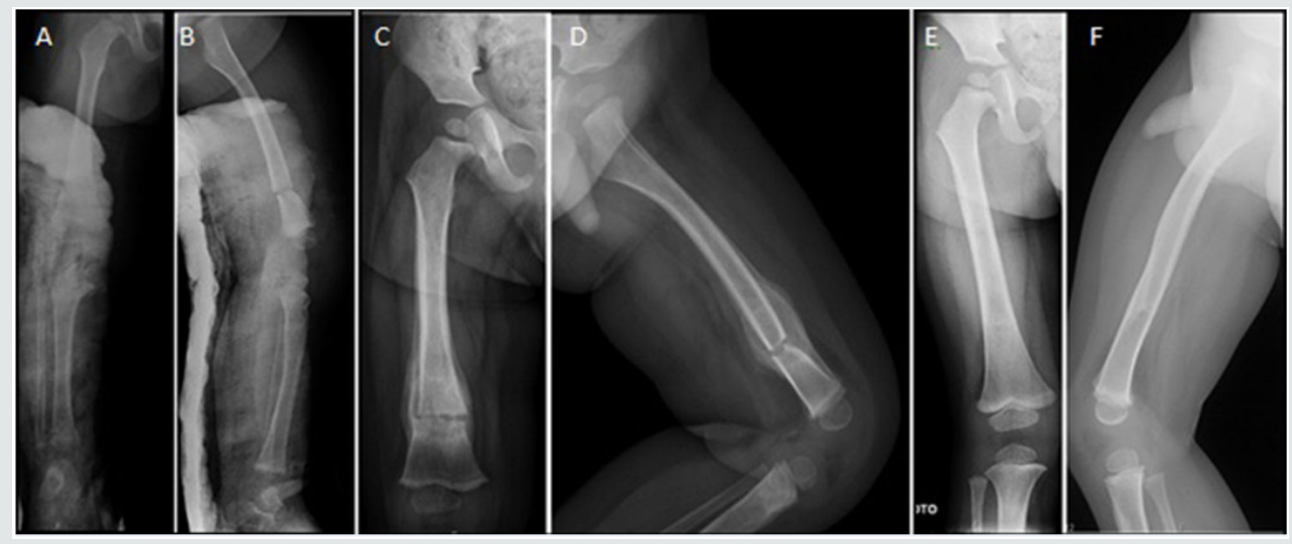

Figure 3: AP and lateral X-Rays of the left limb of a 12 years old boy showing a transverse midshaft femur fracture after being hit by a car. A) transverse midshaft femur fracture with Varus displacement and shortening $>2 \mathrm{~cm}$; B, C) One month after fracture and operative stabilization with an antegrade intramedullary reamed and static nail it is evident a good radiographic callus formation and bone healing; D, E) Radiographic evidence of union with no displacement or shortening after extraction of the nail at 6 months after fracture. 

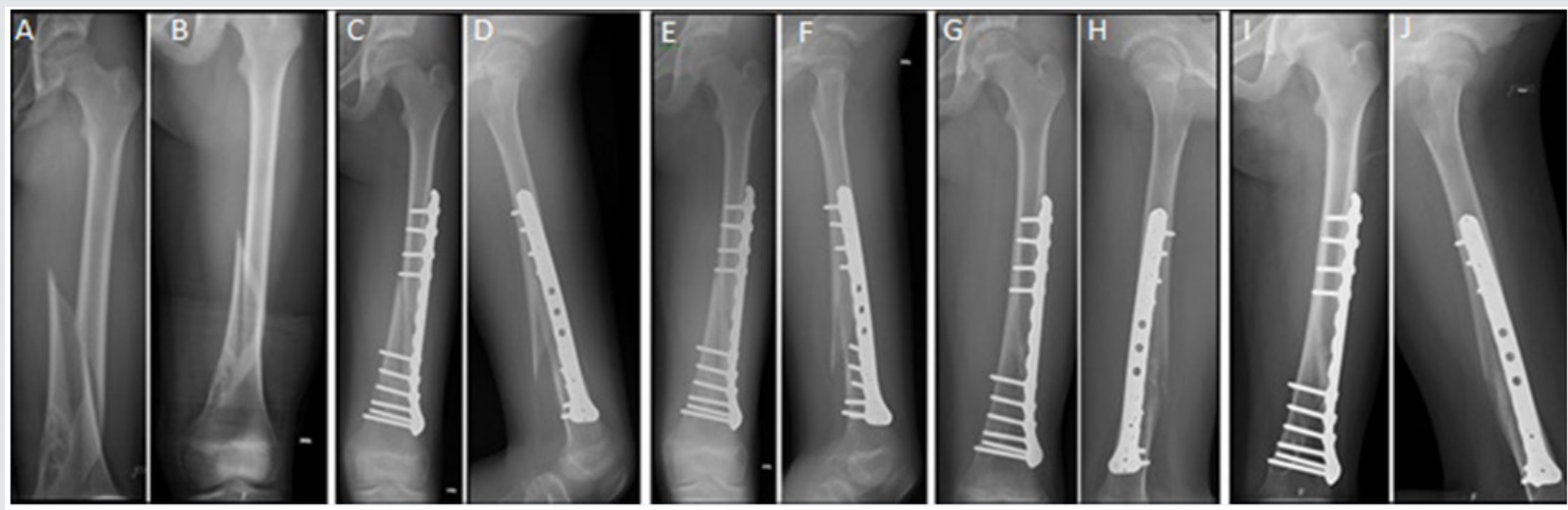

Figure 4: AP and lateral X-Rays of the left limb of an 11 years old girl showing a spiral distal femur fracture after a direct trauma of the thigh while with the knee in hyperflexion. A, B) Spiral distal femur fracture with valgus displacement and shortening $>2 \mathrm{~cm}$; C, D) One month after the fracture and operative stabilization with a closed reduction and fixation with a submuscular plate. It's visible a good Varus/valgus alignment and apposition of the fragments although with a minimal displacement to posterior of the proximal fragment; E, F) Radiographic evidence of union with no displacement or shortening, 6 months after fracture and 8 months after fracture $(\mathrm{G}, \mathrm{H})$; I, J) Radiographic control at 12 months after fracture with a complete bone remodeling.

Duration of hospitalization was significantly different $[p<0.001]$ between patients treated nonoperatively $[4.9 \pm 4.9$ days] and operatively [13.9 \pm 10.5 days]. There were no differences between groups regarding fracture healing time $(6.4 \pm 4.6$ weeks in nonoperative group and $8.3 \pm 5$.2weeks in operative group, $[p=0.041])$ and follow-up time $(42.2 \pm 59.9$ weeks in nonoperative group and $61.5 \pm 51.7$ weeks in operative group, $[\mathrm{p}=0.023]$ ) (Table 1). Of the 54 patients that completed follow-up in our institution, we identified $15 \%$ of complications following treatment [ $n=8]$. Of these, 4 complications were observed after surgical treatment: superficial infection $[n=1]$, elastic nail prominence $[n=1]$, myositis ossificans [n=1] and sciatic neuropraxia [n=1] and 4 complications after conservative treatment: knee flexion contracture [n=1], leg length discrepancy (LLD) [n=3] with 2 nonsymptomatic cases of LLD under $1,5 \mathrm{~cm}$ and one patient with an LLD of $3,2 \mathrm{~cm}$ LLD, partially compensated with a shoe insert. The case of knee stiffness with an initial $30^{\circ}$ flexion contracture was completely resolved after rehabilitation. The case of superficial infection was solved after 6 weeks of oral antibiotics. The single case of elastic nail prominence on the distal femur with associated pain, required additional surgery for partially cutting the nail end, thus getting resolution of the pain. The myositis ossificans was noticed in the posterior distal femur after an antegrade elastic nail and was not related with any pain or discomfort. The sciatic neuropraxia occurred in a 13-yearold obese patient $(70 \mathrm{Kg}$ ) that was submitted to a rigid nailing with a trochanteric nail. This particular patient had a long operative time on the traction table ( 3 hours). The sciatic neuropraxia was noticed upon awaking from general anesthesia and the patient underwent intensive rehabilitation, with complete recovery after 9 months. The frequency of complications was not significantly different between patients treated operatively and non-operatively. $(\mathrm{p}=0.803)$.

\section{Discussion}

In our study, as described in the literature, the midshaft was the most commonly affected site in children with diaphyseal femoral fractures. The mean age at the time of injury was $6.3 \pm 4.9$ years with a median age of 5 years old and with $25 \%$ of patients having more than 12 years of age. These results are similar to those reported in the literature, with a bimodal distribution for age, with a first peak between 2 and 4 years of age and a second peak in mid-adolescence [16]. While in the literature, boys are more commonly affected in a ratio of 2.6:1, we verified a male predominance ratio of 1.9:1. Regarding the mechanism of injury, we found that direct blunt trauma was the most common cause for a femoral shaft fracture in our patients (major or minor fall, traffic accident, hit-by-car or child abuse). We had one confirmed case of non-accidental injury, a 5 months old baby boy, with a distal diaphyseal femoral fracture treated with a Spica cast (Figure 1). Because of his age, this child was properly evaluated and referenced to our multidisciplinary team during the hospitalization time, considering the possibility of child abuse. In these cases, investigation is mandatory, as nonaccidental trauma has been reported as the leading cause of femur fractures in children less than one year old [17-19]. Although AAOS also recommends evaluation of child abuse in all children younger than 36 months with diaphyseal femoral fractures [20], in our institution an universal evaluation is done for all children younger than 12 months, but older children are evaluated on a case-by-case basis, as needed.

At the time of the fracture, $18 \%$ of the patients also had other traumatic lesions such as head trauma with subdural hematoma, brachial plexus neuropraxia, renal trauma, splenic trauma, hepatic trauma and severe thoracic trauma. These lesions occurred mainly as a consequence of high energy trauma mechanism. None of these patients died during admission, hospitalization or follow-up period. We verified that the occurrence of these associated lesions was statistically significantly higher in older and heavier patients. Older patients are commonly more independent in terms of their daily life and assume more risk behaviors. In the decision-making process for treating femoral shaft fractures, one should considerer not only the 
age of the child, but also weight, associated injuries, fracture pattern and mechanism of injury [14-22]. The majority of our patients were treated non-operatively (62\%) and the minimum age at surgery was 6 years. In $76 \%$ of the patients that were treated conservatively, early closed reduction and Spica casting was the primary option, which is supported by the literature [20]. The operated patients were mainly treated with nails (83\%), although osteotaxis and submuscular plates were used in selected cases. In the nailing group, $47 \%$ were treated with elastic nails and the other ones with rigid nails. In the literature, flexible/elastic nails are recommended for length stable fractures and indicated to treat children age 5 to 11 years old and weighing less than $49 \mathrm{~kg}$ [20-29]. The flexible nails are put through small incisions and work as a load sharing device, allowing a relative stability and avoiding the risk of going through the growth plate and permitting early motion and ambulation (48$72 \mathrm{~h}$ ) [14]. Despite these advantages, AAOS guidelines call attention for a worst prognosis with elastic nail in patients older than 10 years of age or weight above $49 \mathrm{Kg}$, favoring rigid nailing for these cases. Rigid nailing is ideal for skeletally mature children and, in our series, it was only considered for patients older than 10 years of age and always through a trochanteric entry, avoiding any piriformis or near piriformis entry due to the risk of avascular necrosis of the femoral head or growth plate disturbances [28-31]. Two of our patients were treated with submuscular plating and other 2 with osteotaxis. In fact, submuscular plating it is not a common surgical option in this type of fracture but, as it is supported in the literature, indirect reduction with submuscular bridge plating is an option for operative comminuted fractures for patients older than 5 years old, such as the two patients of our study [24-32]. The operative stabilization with external fixator was considered in two patients: one patient with 12 years old with an open middle shaft fracture (Type II of Gustillo \& Anderson Classification) after a traffic accident in need of wound debridement and provisional stabilization. This method became the definitive method of treatment in this particular patient. The other patient was a 7 years old child with a closed midshaft fracture with multiple associated lesions (pelvic fracture and braquial plexus neuropraxia) after being hit by a car. This method of fixation is particularly useful when skin integrity is compromised and for initial stabilization of femoral shaft fractures in polytrauma patients, as part of a damage control strategy [2033]. Although a high rate of malunion and pin tract infection is reported with osteotaxis [20-33] we did not find any of those in our two patients.

Age and weight were significantly different between conservatively and surgically treated patients. A higher age $(11.3 \pm 2.6$ years) and weight $(42.5 \pm 13.8 \mathrm{Kg}$ ) was found in the operated group. These results are not surprising, as age and weight are relevant factors in the decision making to choose the adequate treatment for each patient [14-22]. Surgery should also be considered in cases of unacceptable remaining deformity, polytrauma, neurovascular injury or open fracture [28]. We also found statistically significant differences between operated and non-operated patients regarding duration of hospitalization. Operated patients stayed in hospital for longer time, as they more commonly had more severe associated lesions at the moment of the diaphyseal femur fracture. We verified
$15 \%$ of complications after treatment. Out of the 4 complications reported after conservative treatment, 3 cases were LLD in patients between 5 and 9 years old. Overgrowth usually occurs in children with age between 2 and 10 years old, after both conservative and operative treatments. This process occurs more rapidly during the first 2 years after fracture and it happens due to increased vascularity at the growth plate during the process of fracture healing. Some authors found an average lengthening of $9 \mathrm{~mm}$, varying from $4 \mathrm{~mm}$ to $2.5 \mathrm{~cm}$ [34-35]. We found one case of knee stiffness after a conservative treatment of a distal diaphyseal femoral fracture with cruropodalic cast, a complication described in the literature as being more common after conservative treatment [23]. Our patient completely recovered after physiotherapy. We had one patient with an elastic nail prominence, that required a secondary surgical procedure. This complication, described in the literature, is usually related with titanium elastic nails that are left unbent and too long. For this reason, it is always recommendable to palpate the end of the nail to exclude prominence and also to mobilize the knee and verify total range of motion to avoid impingement of the material [36]. The case of myositis ossificans in the posterior distal femur after an elastic nailing was not related with any pain or discomfort and thus only observation was undertaken for this patient. We had one case of sciatic neuropraxia in a 13-year-old obese boy $(70 \mathrm{Kg})$, probably due to the prolonged time in the traction table, while being treated with a trochanteric rigid nail. We didn't observe any case of femoral head osteonecrosis, malunion, nonunion, neurovascular injury, refracture, thromboembolism or fat emboli syndrome [28]. In conclusion, our retrospective cohort study provides valuable epidemiological data about diaphyseal femoral fractures in the pediatric population and may contribute for the development of prevention strategies. We identified weight and age as predictive factors for associated injuries in children with femoral shaft fractures. Prospective comparative studies are needed to enhance our knowledge of how specific fracture treatment may be optimized for different age and weight groups in the pediatric population.

\section{References}

1. Landin LA (1997) Epidemiology of children's fractures. J Pediatr Orthop B 6(2): 79-83.

2. Cooper C, Dennison EM, Leufkens HG, Bishop N, van Staa TP (2004) Epidemiology of childhood fractures in Britain: a study using the general practice research database. J Bone Miner Res 19(12): 1976-1981.

3. Valerio G, Gallè F, Mancusi C, Di Onofrio V, Colapietro M, et al. (2010) Pattern of fractures across pediatric age groups: analysis of individual and lifestyle factors. BMC Public Health 10: 656.

4. Mathison DJ, Agrawal D (2010) An update on the epidemiology of pediatric fractures. Pediatr Emerg Care 26(8): 594-603.

5. Caine D, Caine C, Maffulli N (2006) Incidence and distribution of pediatric sport-related injuries. Clin J Sport Med 16(6): 500-513.

6. Hedström EM, Svensson O, Bergström U, Michno P (2010) Epidemiology of fractures in children and adolescents. Acta Orthop 81(1): 148-153.

7. Schalamon J, Dampf S, Singer G, Ainoedhofer H, Petnehazy T, et al. (2011) Evaluation of fractures in children and adolescents in a Level I Trauma Center in Austria. J Trauma 71(2): 19-25.

8. Brown CV, Neville AL, Salim A, Rhee P, Cologne K, et al. (2006) The impact of obesity on severely injured children and adolescents. J Pediatr Surg 41(1): 88-91. 
9. Lazar-Antman MA, Leet AI (2012) Effects of obesity on pediatric fracture care and management. J Bone Joint Surg Am 94(9): 855-861.

10. Taylor ED, Theim KR, Mirch MC, Ghorbani S, Tanofsky-Kraff M, et al. (2006) Orthopedic complications of overweight in children and adolescents. Pediatrics 117(6): 2167-2174.

11. Dimitri P, Wales JK, Bishop N (2010) Fat and bone in children: differential effects of obesity on bone size and mass according to fracture history. J Bone Miner Res 25(3): 527-536.

12. Dimitri P, Bishop N, Walsh JS, Eastell R (2012) Obesity is a risk factor for fracture in children but is protective against fracture in adults: a paradox. Bone 50(2): 457-466.

13. Joeris A, Lutz N, Wicki B, Slongo T, Audigé L (2014) An epidemiological evaluation of pediatric long bone fractures - a retrospective cohort study of 2716 patients from two Swiss tertiary pediatric hospitals. BMC Pediatr 14: 314.

14. Bhuyan BK, Mohan Singh S (2014) Titanium elastic nailing in pediatric femoral diaphyseal fractures in the age group of 5-16 years - A short term study. J Clin Orthop Trauma 5(4): 203-210.

15. Isik C, Kurtulmus T, Saglam N, Saka G, Akpinar F, et al. (2015) Kirschner wire versus titanium elastic nails in pediatric femoral shaft frcatures. Acta Ortop Bras 23(5): 255-258.

16. Egol K, Koval K, Zuckerman J (2014) Handbook of Fractures. (Ed.) Lippincott Williams \& Wilkins, USA.

17. Hinton RY, Lincoln A, Crockett MM, Sponseller P, Smith G (1999) Fractures of the femoral shaft in children. Incidence, mechanisms, and sociodemographic risk factors. J Bone Joint Surg Am 81(4): 500-507.

18. Hougaard K (1989) Femoral shaft fractures in children: a prospective study of the overgrowth phenomenon. Injury 20(3): 170-172.

19. Femoral Shaft Fractures Guideline Team (2006) Evidence-based care guideline for medical management of femoral shaft fractures Cincinnati Children's Hospital Medical Center.Guideline 22: 1-19.

20. Jevsevar DS, Shea KG, Murray JN, Sevarino KS (2015) AAOS Clinical Practice Guideline on the Treatment of Pediatric Diaphyseal Femur Fractures. J Am Acad Orthop Surg 23(12): 101.

21. Bassett WP, Safier S, Herman MJ, Kozin SH, Abzug JM (2015) Complications of pediatric femoral shaft and distal physeal fractures. Instr Course Lect 64: 461-470.

22. Staheli LT, Sheridan GW (1977) Early spica cast management of femora shaft fractures in young children. A technique utilizing bilateral fixed skin traction. Clin Orthop Relat Res (126): 162-166.
23. Kapil Mani KC, Dirgha Raj RC, Parimal A (2015) Pediatric femoral shaft fractures treated by flexible intramedullary nailing. Chin J Traumatol 18(5): 284-287.

24. Flynn JM, Curatolo E (2015) Pediatric femoral shaft fractures: a system for decision making. Instr Course Lect 64: 453-460.

25. Carey TP, Galpin RD (1996) Flexible intramedullary nail fixation of pediatric femoral fractures. Clin Orthop Relat Res (332): 110-118.

26. Canale S (2007) Fracture and dislocation in children. Campbell's Operative Orthopaedics 11th (Ed.), Philadelphia: Mosby pp: 1651-1661.

27. Beaty J, Kasser J (2010) Fractures in Children. 7th (ed.), Philadelphia: Lippincott, Williams \& Wilkins. USA.

28. Dickens A (2013) Management of Pediatric Femur Shaft Fractures. UNM Orthopaedic Research Journal 2(1): 11.

29. Moroz LA, Launay F, Kocher MS, Newton PO, Frick SL, et al. (2006) Titanium elastic nailing of fractures of the femur in children. Predictors of complications and poor outcome. J Bone Joint Surg Br 88(10): 13611366.

30. Jencikova-Celerin L, Phillips JH, Werk LN, Wiltrout SA, Nathanson I (2008) Flexible interlocked nailing of pediatric femoral fractures: experience with a new flexible interlocking intramedullary nail compared with other fixation procedures. J Pediatr Orthop 28(8): 864-873.

31. Kanellopoulos AD, Yiannakopoulos CK, Soucacos PN (2006) Closed, locked intramedullary nailing of pediatric femoral shaft fractures through the tip of the greater trochanter. J Trauma 60(1): 217-222.

32. Sink EL, Hedequist D, Morgan SJ, Hresko T (2006) Results and technique of unstable pediatric femoral fractures treated with submuscular bridge plating. J Pediatr Orthop 26(2): 177-181.

33. Barlas K, Beg H (2006) Flexible intramedullary nailing versus external fixation of paediatric femoral fractures. Acta Orthop Belg 72(2): 159163.

34. Griffin PP, Green WT (1972) Fractures of the shaft of the femur in children: treatment and results. Orthop Clin North Am 3(1): 213-224.

35. Shapiro F (1981) Fractures of the femoral shaft in children. The overgrowth phenomenon. Acta Orthop Scand 52(6): 649-55.

36. Salonen A, Lahdes-Vasama T, Mattila VM, Välipakka J, Pajulo O (2015) Pitfalls of femoral titanium elastic nailing. Scand J Surg 104(2):121-126.
This work is licensed under Creative Commons Attribution 4.0 License

To Submit Your Article Click Here:

Submit Article

\section{Orthopedics and Sports Medicine Open Access Journal

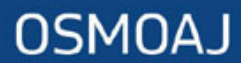

DOI: $10.32474 /$ OSMOAJ.2020.03.000172

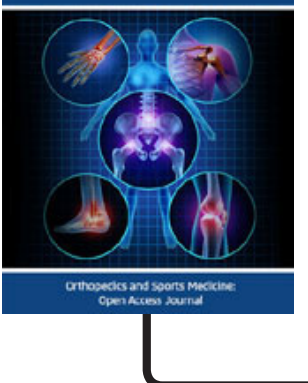

\section{Assets of Publishing with us}

- Global archiving of articles

- Immediate, unrestricted online access

- Rigorous Peer Review Process

- Authors Retain Copyrights

- Unique DOI for all articles 